\title{
Burnout and imposter syndrome among Saudi young adults
}

\section{The strings in the puppet show of psychological morbidity}

Saad Alrayyes, MBBS, Umar F. Dar, MBBS, FCPS, Musab Alrayes, MBBS, Ahmed Alghutayghit, MBBS, Nouf Alrayyes, MBBS.

\begin{abstract}
الأهداف : تحديد مدى انتشار متلازمة الاحتيال (IS ) بين البالغين السعوديين

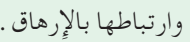

المنهجية : باستخدام أخذ العينات المُلاَوَمَة غير الاحتمالية ، أجرينا دراسة تحليلية

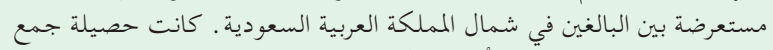

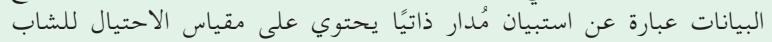

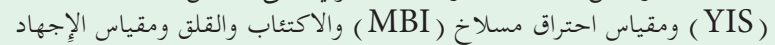

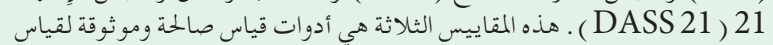
IS

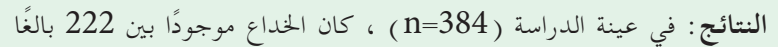

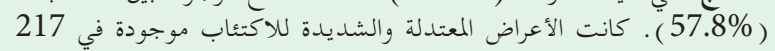

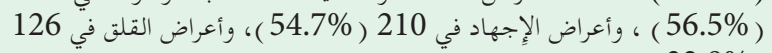

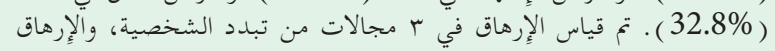

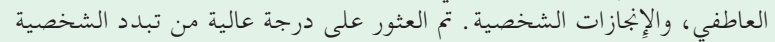

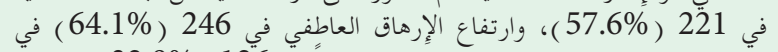

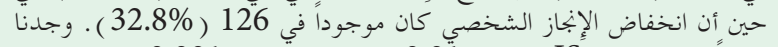

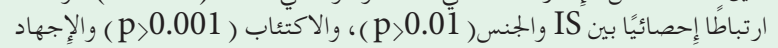

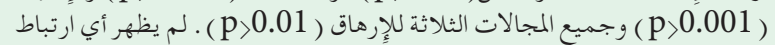

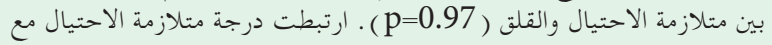
جميع مجالات الإرهاق الثلاثة حتى بعد السيطرة على الاكتئاب والقلق والإِجهاد.

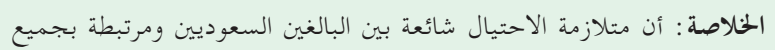

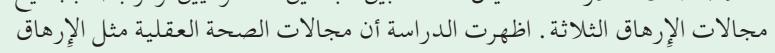
والاكتئاب والضغط والقلق مرتبطة مع متلازمة الاحتيال.
\end{abstract}

Objectives: To determine the prevalence of imposter syndrome (IS) among Saudi adults and its association with burnout.

Methods: Using non-probability convenience sampling, we carried out a cross-sectional analytical study among adults in Northern Saudi Arabia. Data collection toll was a self-administered questionnaire containing young imposter scale (YIS), Maslach burnout inventory (MBI) and depression, anxiety, and stress scale 21 (DASS 21). These 3 scales are valid and reliable measurement tools for measuring IS, burnout, and psychological morbidity.
Results: In the study sample $(\mathrm{n}=384)$, imposterism was present among 222 adults (57.8\%). Moderate and severe symptoms of depression were present in 217 (56.5\%), symptoms of stress in $210(54.7 \%)$, and symptoms of anxiety in $126(32.8 \%)$. Burnout was measured in 3 domains of depersonalization, emotion exhaustion, and personal accomplishments. High degree of depersonalization was found in 221 (57.6\%), higher emotional exhaustion in 246 (64.1\%) while lower personal accomplishment was present in $126(32.8 \%)$. We found statistical association between IS and gender $(p<0.01)$, depression $(p<0.001)$ stress $(p<0.001)$ and all 3 domains of burnout $(p<0.01)$. Imposter syndrome was not found associated with anxiety $(p=0.97)$. Young imposter scale score was associated with all the 3 domains of burnout even after controlling for depression, anxiety, and stress.

Conclusion: Imposter syndrome is frequent among Saudi adults and associated with all 3 burnout domains. Mental health domains like burnout, depression, stress, and anxiety were found associated with IS.

Keywords: depression, stress, anxiety, imposterism, depersonalization, emotional exhaustion, personal accomplishment

Saudi Med J 2020; Vol. 41 (2): 189-194 doi: 10.15537/smj.2020.2.24841

From the College of Medicine (Alrayyes $S$, Alghutayghit, Alrayyes $N$ ), from the Department of Community \& Family Medicine (Dar), Jouf University; and from the Department of Internal Medicine (Alrayes M), Prince Mutaib Bin Abdulaziz Hospital, Sakaka, Kingdom of Saudi Arabia.

Received 1st July 2019. Accepted 5th December 2019

Address correspondence and reprint request to: Dr. Umar F. Dar, Department of Community and Family Medicine, Jouf University, Sakaka, Kingdom of Saudi Arabia. Email: ufdar@ju.edu.sa ORCID ID: 0000-0003-2149-2190 
Tmposter syndrome (IS) or "imposter phenomenon" was first described among high-achieving woman who believed that they were less intelligent or less capable than what others perceived them to be. ${ }^{1}$ Since then, the term IS was observed and documented for both genders at similar levels and has been used to characterize the internal feeling of self-doubt, inadequacy, and feeling of being detected as intellectual fraud..$^{2-5}$ Despite evidence of competence, those suffering from imposterism attribute their lifetime achievements and successes to external conditions such as luck and chance. They negatively assess their own abilities to replicate these successes, resulting in low levels of self-efficacy, anxiety, and depression. ${ }^{6}$ Imposter phenomenon may in fact interlink with burnout; however, the one-to-one relationship lacks sufficient data to prove the association. $5,7,8$

Dimensions of mental health ranges from stress, anxiety and depression, emotional exhaustion, and burnout. Burnout is a triad of 3 phenomena, example emotional exhaustion (loss of motivation to work), sense of low personal accomplishment, and depersonalization (feelings of cynism). ${ }^{9-13}$ Going forward, from the foundations established by Maslach et al, ${ }^{14-16}$ researchers have reported burnout to be more frequently associated with inter-alia of negative consequences such as mood disorders, debilitations in the quality of life, high stress level, and sleep deprivation.

Adulthood is a period of onset and maturation of behaviors and habits that influence later life. Mental and psychological disorders develop in mid- to late adolescence and add to the existing burden of disease among adolescents and become evident later in life. ${ }^{17,18}$ There is lack of studies regarding interaction between IS and other psychological morbidities. A pilot study among medical students have tried to discover the association between IS and burnout. ${ }^{7}$ Imposters believe that they are just posing to develop self-actualization. This is an overlapping area with burnout domain of low personal accomplishment. Depersonalization and emotional exhaustion lead to the behavior of acting as 'non-self' for long times. This is a possible explanation for an interaction between IS and burnout. $2,3,5,7$

There is lack of research on IS and burnout among young adults living in Saudi Arabia. Studies regarding

Disclosure. Authors have no conflict of interests, and the work was not supported or funded by any drug company. interaction among IS, burnout and psychological morbidity are rare. We carried out this study to determine the prevalence of IS, burnout, and psychological morbidity along with their interaction with each other among adult Saudi population.

Methods. We carried out a cross-sectional analytical survey after approval of proposal from local ethical review committee among young adults attending different educational institutes in Al-Jouf region of Saudi Arabia. The sampling population was the recent graduates and interns from the colleges of medicine, dentistry, allied health sciences, and pharmacy. A convenient non-probability sampling technique was used to recruit participants. Using the WHO sample size calculator, targeted sample size was 385 adults, taking expected prevalence of IS approximately 50\% at $95 \%$ confidence level and 5\% margin error. Due to scarcity of data in this area, the expected prevalence was considered $50 \%$ in order to obtain higher sample size. All Saudi adults of age 18 to 25 years and of either gender were eligible to be included in this study. The adults can be interns or recent graduates.

We distributed a link for web-based, anonymous questionnaire to the eligible candidates (thru e-mail, social media groups, sports, and college groups) between December 2018 and May 2019 targeting a population of approximately 500 adults recently graduated from medical, dental, pharmacy, and allied health colleges. In the covering letter, we provided sufficient information on the study in plain language before filling the questionnaire We considered its completion as an informed consent. We received responses from 390 participants with a response rate of $78 \%$. Six forms were deleted due to incomplete data $(n=384)$. The participation in the study was voluntary. The present study was approved by the Institutional Review Board at Jouf University, Sakaka, Saudi Arabia (13-3-4/3839). The study was carried out in accordance with the ethical standards according to the Helsinki Declaration.

It consisted of demographic data and 3 scales: young imposter scale (YIS) to measure imposterism; Maslach burnout inventory - human services survey (MBI-SS) to measure burnout; and depression, anxiety, and stress scale 21 (DASS-21) for psychological morbidity.

Young imposter scale is a valid and reliable inventory to screen IS. ${ }^{7}$ Its composed of 8 -item questionnaire to dichotomously assess the presence or absence of IS among young adults. Participants were considered having an IS if they scored 5 or higher using the 8-item "yes" or "no" questions."

Maslach burnout inventory - human services survey is a questionnaire to measure burnout among adults 
across 3 domains. The MBI-SS is well recognized, valid and reliable tool. ${ }^{12,19,-23}$ The Cronbach alpha for Arabic translation was $0.81 .^{24}$ Its composed of 22 statements covering degrees of burnout across 3 domains of emotional exhaustion, depersonalization, and personal accomplishment. We operationally defined burnout as high emotional exhaustion or depersonalization subscales (emotional exhaustion $\geq 27$ or depersonalization subscales $\geq 10$ ) or low sub score on personal accomplishment (<33 points). ${ }^{9,12,24-26}$

To measure psychological morbidity, we used a validated 21-items DASS-21.27,28 The Arabic version of DASS-21 has cronbach alpha level of $0.88 .{ }^{28}$ Scores were calculated for depression, anxiety, and stress subscales by summing the scores for each subscale and multiplying by 2 . In subcategories of DASS, depression score $\geq 14$, anxiety score $\geq 10$, and stress score $\geq 19$ were considered positive findings. ${ }^{28}$

Statistical analysis. The collected data was performed using the Statistical Package for Social Sciences version 20.0 (IBM Corp, Armonk, NY, USA). Continuous variable like age and scores of different scales were presented as mean $\pm \mathrm{SD}$ while categorical variables were described as frequency and percentage. We applied Chi-square test or Fisher t-test (as appropriate) to determine the statistical difference across categorical variables. Variables with $p<0.1$ were entered for binary logistic regression analysis to predict imposterism across 3 domains of burnout. A $p$ value of $<0.05$ was considered as statistically significant.

Results. In this study, mean $\pm S D$ of the study population was $19.9 \pm 2.1$ years. There was almost equal participation with female $54.7 \%$ and male $45.3 \%$. Among sampled population $(\mathrm{n}=384)$, IS was present in $57.8 \%$. Moderate and severe symptoms of depression were present in $56.5 \%$, stress in $54.7 \%$, and anxiety in $32.8 \%$ adults (Table 1 ).

Burnout was measured in 3 domains of depersonalization, emotion exhaustion, and personal accomplishments. High degree of depersonalization was found in $57.6 \%$, higher emotional exhaustion in $64.1 \%$ while lower personal accomplishment was present in $32.8 \%$ (Table 2).

We found statistical association between IS and gender $(p<0.01)$, depression $(p<0.001)$ stress $(p<0.001)$, and all 3 domains of burnout $(p<0.01)$. Imposter syndrome was not found associated with anxiety $(p=0.97)$ (Table 3). When we predicted burnout score in 3 domains by imposterism and psychological morbidity scores, we found that imposterism, depression and stress significantly predicted scores for burnout (Table 4).
Table 1 - Baseline characteristics, imposterism and psychological morbidity among sampled population (N=384).

\begin{tabular}{lc}
\hline Characteristics & $\mathbf{n}(\%)$ \\
\hline Age & \\
Age in years (mea \pm SD) & $19.9 \pm 2.1$ \\
$\quad<18$ & $56(14.6)$ \\
$18-20$ & $174(45.3)$ \\
$21-23$ & $124(32.3)$ \\
24 & $30(7.8)$ \\
Gender & \\
Male & $174(45.3)$ \\
Female & $210(54.7)$ \\
Imposter syndrome presence & \\
Imposter score (median, Q1, Q3) & $15,8,21$ \\
Yes & $222(57.8)$ \\
No & $162(42.2)$ \\
Depression symptoms (moderate/severe) & \\
Depression score (median, Q1, Q3) & $19,4,22$ \\
Yes & $217(56.5)$ \\
No & $167(43.5)$ \\
Stress symptoms (moderate/severe) & \\
Stress score (median, Q1, Q3) & $13,4,21$ \\
Yes & $210(54.7)$ \\
No & $174(45.3)$ \\
Anxiety symptoms (moderate/severe) & \\
Anxiety score (median, Q1, Q3) & $15,8,21$ \\
Yes & $126(32.8)$ \\
No & $258(67.2)$ \\
\hline \multicolumn{2}{c}{} \\
\hline
\end{tabular}

Table 2 - Categorization of burnout among sampled population ( $\mathrm{N}=384)$.

\begin{tabular}{lccccccc}
\hline Parameters & Median Q1 & Q3 & $\begin{array}{c}\text { High } \\
\mathrm{n}(\%)\end{array}$ & $\begin{array}{c}\text { Moderate } \\
\mathrm{n}(\%)\end{array}$ & $\begin{array}{c}\text { Low } \\
\mathrm{n}(\%)\end{array}$ & $\begin{array}{c}\text { Scores } \\
(\mathrm{mean} \pm \mathrm{SD})\end{array}$ \\
\hline $\begin{array}{l}\text { Depersonalization } \\
\begin{array}{l}\text { Personal } \\
\text { accomplishment }\end{array}\end{array}$ & 15 & 7 & 27 & $221(57.6)$ & $80(20.8)$ & $83(21.6)$ & $16.9 \pm 12.1$ \\
$\begin{array}{l}\text { Emotional } \\
\text { exhaustion }\end{array}$ & 32 & 21 & 36 & $98(25.5)$ & $160(41.7)$ & $126(32.8)$ & $34.2 \pm 8.1$ \\
\hline
\end{tabular}

Discussion. In our study, we found that IS is highly prevalent among young adults in Saudi Arabia. Approximately $57.8 \%$ of the participating young adults were found suffering IS. These results are of great importance as the burden of long-term mental health deficits are prevailing and represent a major public health challenge. Our finding of the high prevalence of IS is consistent with previous literature in the United States and other developed countries. ${ }^{5,7,8}$ However, inclusion of depression, stress, and anxiety measures helped us draw a more specific comparison. Nevertheless, other studies $^{7}$ related to impostorism have used self-reported measures (example: YIS) as those in our study.

In our study, an important finding is that more than 
Table 3 - Association of psychological morbidity with imposter syndrome.

\begin{tabular}{lccc}
\hline Variables & Imposterism & $\begin{array}{c}\text { No } \\
\text { imposterism }\end{array}$ & $P$-value* \\
\hline Gender & $\mathrm{n}(\%)$ & $\mathrm{n}(\%)$ & \\
$\quad$ Male & $88(50.6)$ & $86(49.4)$ & 0.009 \\
$\quad$ Female & $134(63.8)$ & $76(36.2)$ & \\
$\begin{array}{l}\text { Presence of depression } \\
\text { symptoms }\end{array}$ & & & \\
$\quad$ Yes & $151(69.6)$ & $66(30.4)$ & $<0.001$ \\
$\quad$ No & $71(42.5)$ & $96(57.5)$ & \\
$\begin{array}{l}\text { Presence of stress } \\
\text { symptoms }\end{array}$ & & & \\
$\quad$ Yes & $162(77.1)$ & $48(22.9)$ & $<0.001$ \\
$\quad$ No & $60(34.5)$ & $114(65.5)$ & \\
Presence of anxiety & & & \\
symptoms & & & \\
Yes & $73(57.9)$ & $53(42.1)$ & 0.973 \\
$\quad$ No & $149(57.8)$ & $109(42.2)$ & \\
\hline \multicolumn{4}{c}{ Chi-square } \\
\hline
\end{tabular}

Table 4 - Association of burnout parameters with Imposter syndrome and psychological morbidity.

\begin{tabular}{|c|c|c|c|c|}
\hline Parameters & High & Moderate & Low & $P$-value \\
\hline Depersonalization & $\mathrm{n}=221$ & $\mathrm{n}=80$ & $\mathrm{n}=83$ & \\
\hline Imposterism & $183(82.8)$ & $32(40.0)$ & $7 \quad(8.4)$ & $<0.001$ \\
\hline Depression & $152(68.8)$ & $53(66.3)$ & $12(14.5)$ & $<0.001$ \\
\hline Stress & $158(71.5)$ & $36(45.0)$ & $16(19.3)$ & $<0.001$ \\
\hline Anxiety & $61(27.6)$ & $35(43.8)$ & $30(36.1)$ & 0.024 \\
\hline $\begin{array}{l}\text { Personal } \\
\text { accomplishment }\end{array}$ & $\mathrm{n}=98$ & $\mathrm{n}=160$ & $\mathrm{n}=126$ & \\
\hline Imposterism & $80(81.6)$ & $75(46.9)$ & $67(53.2)$ & $<0.001$ \\
\hline Depression & $94(95.9)$ & $98(61.3)$ & $25(19.8)$ & $<0.001$ \\
\hline Stress & $97(99.0)$ & $30(18.8)$ & 83 (65.9) & $<0.001$ \\
\hline Anxiety & $76(77.6)$ & $23(14.4)$ & $27(21.4)$ & $<0.001$ \\
\hline $\begin{array}{l}\text { Emotional } \\
\text { exhaustion }\end{array}$ & $n=246$ & $\mathrm{n}=59$ & $\mathrm{n}=79$ & \\
\hline Imposterism & $130(52.8)$ & $47(79.7)$ & $45(57.0)$ & 0.001 \\
\hline Depression & $161(65.4)$ & $8(13.6)$ & $48(60.8)$ & $<0.001$ \\
\hline Stress & $147(59.8)$ & $54(91.5)$ & $9(11.4)$ & $<0.001$ \\
\hline Anxiety & 95 (38.6) & $12(20.3)$ & $19(24.1)$ & 0.005 \\
\hline
\end{tabular}

Table 5 - Prediction of burnout categories based on psychological morbidity and imposterism groups.

\begin{tabular}{|c|c|c|c|c|c|c|c|c|c|c|c|c|}
\hline & \multicolumn{4}{|c|}{ High \& moderate depersonalization } & \multicolumn{4}{|c|}{ Low personal accomplishment } & \multicolumn{4}{|c|}{ High \& moderate emotional exhaustion } \\
\hline & \multirow[t]{2}{*}{ OR } & \multicolumn{2}{|c|}{$95 \% \mathrm{CI}$ for OR } & \multirow[t]{2}{*}{$P$-value } & \multirow[t]{2}{*}{ OR } & \multicolumn{2}{|c|}{$95 \% \mathrm{CI}$ for OR } & \multirow[t]{2}{*}{ P value } & \multirow[t]{2}{*}{ OR } & \multicolumn{2}{|c|}{$95 \% \mathrm{CI}$ for OR } & \multirow[t]{2}{*}{$P$-valuc } \\
\hline & & Upper & Lower & & & Upper & Lower & & & Upper & Lower & \\
\hline Gender (male) & -1.09 & 0.15 & 0.76 & 0.009 & 0.28 & 0.16 & 0.50 & $<.001$ & 2.44 & 1.30 & 4.6 & 0.006 \\
\hline Imposterism (no) & -1.69 & 0.07 & 0.48 & 0.001 & 2.16 & 1.037 & 4.50 & 0.040 & 6.12 & 2.66 & 14.09 & $<0.001$ \\
\hline Depression (no) & -3.06 & 0.02 & 0.11 & $<0.001$ & 9.44 & 5.23 & 17.04 & $<.001$ & 0.68 & 0.31 & 1.44 & 0.309 \\
\hline Stress (no) & -3.31 & 0.01 & 0.13 & $<0.001$ & 0.178 & 0.08 & 0.37 & $<.001$ & 0.01 & 0.01 & 0.03 & $<0.001$ \\
\hline Anxiety (no) & 2.76 & 4.21 & 59.6 & $<0.001$ & 3.66 & 1.84 & 7.24 & $<.001$ & 5.34 & 2.13 & 13.38 & $<0.001$ \\
\hline Nagelkerke's R ${ }^{2}$ & \multicolumn{4}{|c|}{0.652} & \multicolumn{4}{|c|}{0.454} & \multicolumn{4}{|c|}{0.435} \\
\hline
\end{tabular}

half of those who were affected by IS were females. The significance of gender implications and its association in the development of IS was already hypothesized in the earliest studies that investigated IS. ${ }^{1}$ Previous studies have found that IS may have in fact has a behavioral and personality trait origins. ${ }^{29,30}$ Moreover, our finding is also consistent with a recent study by Vilwock et al, ${ }^{7}$ where they found among young adults in the United States that approximately a third of young female adults had IS. In another study by Henning et $\mathrm{al},{ }^{31}$ female gender was found positively correlated with IS symptoms based on a sample carried out among students. In contrast, several studies have found no significant correlations between gender and IS. ${ }^{9,29}$ One may also speculate that factors inter-linked by gender are predictive of IS rather than gender alone. In a study by Badawy et $\mathrm{al},{ }^{29}$ it was found that negative feedback and high accountability leads to different responses between male and female imposters. They concluded that there was a complex relationship between gender and IS which may vary with context.

A growing body of literature focuses on investigating burnout in lieu of IS, especially after reports showing a $10 \%$ increase of burnout over a 3 -year period in the United States. ${ }^{32}$ Burnout, by definition, is a triad of depersonalization, emotional exhaustion, and poor sense of personal accomplishment. ${ }^{33}$ In a study carried out among adult physicians, Martini et al ${ }^{34}$ reported an overall burnout rate of $50 \%$ with a ranged of $27 \%$ to $75 \%$. In another study, half of the physicians who met the criteria of burnout, considered leaving their jobs and their established careers. ${ }^{35}$ Disturbingly, these reports of burnout are similar to other documented reports among adolescence. ${ }^{17,18}$ Our findings, in agreement with other studies, reveal high levels of burnout subscales among most young adults. ${ }^{13,19,31}$

There exists a paucity of studies relating IS to burnout, but a positive correlation has been observed between IS and burnout among adults. Our results 
are consistent with previous reports; participants who met the criteria of IS were more likely to report feelings of burnout. ${ }^{7-9}$ Perhaps of even greater importance is that high levels of depersonalization, and sense of personal accomplishment were found to be more prevalent than emotional exhaustion among young adult who were affected by IS. It has been theorized that depersonalization and a low sense of personal accomplishments are coping mechanisms emerging subsequently of emotional exhaustion. Our finding suggests that IS might also contribute to the development of burnout and may be an independent factor leading to experiencing depersonalized attitudes without attribution to emotional exhaustion. ${ }^{36}$ The possibility of developing depersonalization behavior without precedent of emotional exhaustion is supported by other studies; however, they were only conducted among adults with burnout feelings. ${ }^{37}$

Many mental health disorders emerge in late childhood and early adolescence and contribute to the burden of psychiatric disorders among young people and their later period in life. In a study by Jones et al, ${ }^{36}$ they found that over $50 \%$ of adult mental disorders had their onset before the age of 18 . Thus, the psychological comorbidities of IS and burnout cannot be ignored. Among other potential psychiatric comorbidities, we found an association between depression, stress, and IS symptoms among young adults. ${ }^{2,38}$ However, it remains to be unclear from our findings weather IS symptoms caused stress and depression, weather stress and depression make one more prone to develop IS symptoms, or if both are interlinked to unknown shared independent variable. These results highlight the fact that the burden of IS is intertwined with many potential psychiatric deficits and may prevail to long-term disabilities.

The psychological literature offers limited approaches to assist those with IS symptoms. Psychologists have recommended frequent, tailored feedback to help those with IS symptoms. Furthermore, timing of tailored feedbacks is crucial to clarify the behavior that an individual with IS felt as imposterism and demonstrate why other perceive them as qualified. ${ }^{2,38}$ Furthermore, some authors have advised against generalized feedback as it might exacerbates the feelings of IS. ${ }^{29}$ Lastly, it was recommended to increase carefulness in designing time management strategies in individuals with IS to avoid exacerbating of imposterism feelings.

Study limitations. A significant limitation of our study is lack of normative data for YIS in general. Another limitation is that our sample was a convenience sample of young adults in Northern region who may not represent young adults across the nation. Lastly, the associations are measured using a cross-sectional design, which may not provide a well-established casualty. The current study include non-probability convenience sampling and cross-sectional nature of study to predict causal association between burnout and IS

In conclusion, the IS and burnout is highly prevalent among Saudi adults. We found an association of burnout with IS in all 3 domains of depersonalization, emotional exhaustion, and low personal accomplishments. The mental and psychological health of adults in northern Saudi Arabia calls for preventive measures. Primary preventive measures to identify and treat IS are available. Peer interaction and open discussions regarding psychological morbidity may reduce the self-doubt among our capable adults and help them grow with prosperity and content. Although a direct causal relationship between burnout and IS or psychological morbidity cannot be concluded from this data, we found strong interlink between these phenomena.

Other practical implications of this study include 3600 feedback to reduce the effects of IS, standard operating procedures for new interns in health sector, leadership, and management skills for coping the work-site pressures and innovative leadership style. This Northern Saudi Arabia discussed the important issue of the young generation. Nevertheless, we recommend providing regular, tailored, positive feedbacks to individuals with IS symptoms.

Acknowledgment. The authors gratefully acknowledge the participants for providing their responses. The authors would like to thank SCREBENDI (www.screbendi.com) for English language editing.

\section{References}

1. Clance PR, Imes SA. The imposter phenomenon in high achieving women: dynamics and therapeutic intervention. Psychol Psychother-T 1978; 15: 241-247.

2. Mullangi S, Jagsi R. Imposter syndrome: treat the cause, not the symptom. JAMA 2019; 322: 403-404.

3. Gallagher SR. Professional identity and imposter syndrome. Clin Teach 2019; 16: 426-427.

4. LaDonna KA, Ginsburg S, Watling C. "Rising to the level of your incompetence": What physicians' self-assessment of their performance reveals about the imposter syndrome in medicine. Acad Med 2018; 93: 763-768.

5. Persky AM. Intellectual self-doubt and how to get out of it. Am J Pharm Educ 2018; 82: 6990.

6. Russell R. On overcoming imposter syndrome. Acad Med 2017; 92: 1070.

7. Villwock JA, Sobin LB, Koester LA, Harris TM. Impostor syndrome and burnout among American medical students: a pilot study. Int J Med Educ 2016; 7: 364-369.

8. Leung L. Using perfectionism, imposter phenomenon and occupational field to predict job burnout. Long Beach (CA): ProQuest Publishing; 2006. 
9. Leach PK, Nygaard RM, Chipman JG, Brunsvold ME, Marek AP. Impostor phenomenon and burnout in general surgeons and general surgery residents. J Surg Educ 2019; 76: 99-106.

10. Aldubai SAR, Aljohani AM, Alghamdi AG, Alghamdi KS, Ganasegeran K, Yenbaawi AM. Prevalence and associated factors of burnout among family medicine residents in Al Madina, Saudi Arabia. J Family Med Prim Care 2019; 8: 657-662.

11. Bany Hamdan A, Alshammary S, Javison S, Tamani J, AlHarbi M. Burnout among healthcare providers in a comprehensive cancer center in Saudi Arabia. Cureus 2019; 11: e3987.

12. Alqahtani AM, Awadalla NJ, Alsaleem SA, Alsamghan AS, Alsaleem MA. Burnout Syndrome among emergency physicians and nurses in Abha and Khamis Mushait Cities, Aseer Region, Southwestern Saudi Arabia. ScientificWorldJournal 2019; 2019: 4515972.

13. Altannir Y, Alnajjar W, Ahmad SO, Altannir M, Yousuf F, Obeidat A, et al. Assessment of burnout in medical undergraduate students in Riyadh, Saudi Arabia. BMC Med Educ 2019; 19: 34.

14. Maslach C, Jackson SE. The measurement of experienced burnout. J Occup Behav 1981; 2: 99-113.

15. Maslach C, Jackson SE, Leiter MO, Schaufeli WB, Schwab RL, editors. MBI: Maslach burnout inventory. 3rd ed. Palo Alto (CA): Consulting Psychologists Press; 1981.

16. Maslach C, Schaufeli WB, Leiter MP. Job burnout. Annu Rev Psychol 2001; 52: 397-422.

17. Dick B, Ferguson BJ. Health for the world's adolescents: a second chance in the second decade. J Adolesc Health 2015; 56 : 3-6.

18. World Health Organization. Health for the world's adolescents: a second chance in the second decade: summary. 2014. [December 2018. Cited May 2019]. Available from URL: https://www.who.int/maternal_child_adolescent/documents/ second-decade/en/

19. Almalki SA, Almojali AI, Alothman AS, Masuadi EM, Alaqeel MK. Burnout and its association with extracurricular activities among medical students in Saudi Arabia. Int J Med Educ 2017; 8: $144-150$.

20. Aldrees T, Hassouneh B, Alabdulkarim A, Asad L, Alqaryan S, Aljohani E, et al. Burnout among plastic surgery residents. National survey in Saudi Arabia. Saudi Med J 2017; 38: 832-836.

21. Mudallal RH, Othman WM, Al Hassan NF. Nurses' burnout: the influence of leader empowering behaviors, work conditions, and demographic traits. Inquiry 2017; 54: 46958017724944.

22. Elbarazi I, Loney T, Yousef S, Elias A. Prevalence of and factors associated with burnout among health care professionals in Arab countries: a systematic review. BMC Health Serv Res 2017; 17: 491.

23. Alharbi J, Wilson R, Woods C, Usher K. The factors influencing burnout and job satisfaction among critical care nurses: a study of Saudi critical care nurses. J Nurs Manag 2016; 24: 708-717.
24. Abdo S, El-Sallamy R, El-Sherbiny A, Kabbash I. Burnout among physicians and nursing staff working in the emergency hospital of Tanta University, Egypt. East Mediterr Health 2016; 21: 906-915.

25. Ghali RR, Boulos DN, Alorabi M. Cross-Sectional Study of Burnout among a Group of Egyptian Oncologists at Ain Shams University. Research in Oncology. 2019; 15: 26-30.

26. See KC, Zhao MY, Nakataki E, Chittawatanarat K, Fang WF, Faruq MO, et al. Professional burnout among physicians and nurses in Asian intensive care units: a multinational survey. Intensive Care Med 2018; 44: 2079-2090.

27. Gloster AT, Rhoades HM, Novy D, Klotsche J, Senior A, Kunik $\mathrm{M}$, et al. Psychometric properties of the depression anxiety and stress scale-21 in older primary care patients. J Affect Disord 2008; 110: 248-259.

28. Ali AM, Ahmed A, Sharaf A, Kawakami N, Abdeldayem SM, Green J. The Arabic version of the depression anxiety stress scale-21: cumulative scaling and discriminant-validation testing. Asian J Psychiatr 2017; 30: 56-58.

29. Badawy RL, Gazdag BA, Bentley JR, Brouer RL. Are all impostors created equal? Exploring gender differences in the impostor phenomenon-performance link. Pers Individ Dif 2018; 131: 156-163.

30. Ross SR, Krukowski RA. The imposter phenomenon and maladaptive personality: Type and trait characteristics. Pers Individ Dif 2003; 34: 477-484.

31. Henning K, Ey S, Shaw D. Perfectionism, the imposter phenomenon and psychological adjustment in medical, dental, nursing and pharmacy students. Med Educ 1998; 32: 456-464.

32. Shanafelt TD, Hasan O, Dyrbye LN, Sinsky C, Satele D, Sloan $\mathrm{J}$, et a. Changes in burnout and satisfaction with work-life balance in physicians and the general US working population between 2011 and 2014. Mayo Clin Proc 2015: 90: 1600-1613.

33. Maslach C, Leiter MP. Understanding the burnout experience: recent research and its implications for psychiatry. World Psychiatry 2016; 15: 103-111.

34. Martini S, Arfken CL, Churchill A, Balon R. Burnout comparison among residents in different medical specialties. Acad Psychiatry 2004; 28: 240-242.

35. Dishop CR, Green AE, Torres E, Aarons GA. Predicting turnover: the moderating effect of functional climates on emotional exhaustion and work attitudes. Community Ment Health J 2019; 55: 1-9.

36. Jones PB. Adult mental health disorders and their age at onset. Br J Psychiatry Suppl 2013; 202: s5-s10.

37. Legassie J, Zibrowski EM, Goldszmidt MA. Measuring resident well-being: impostorism and burnout syndrome in residency. $J$ Gen Intern Med 2008; 23: 1090-1094.

38. Ramsey JL, Spencer AL. Interns and imposter syndrome: proactively addressing resilience. Med Educ 2019; 53: 504-505. 